\title{
Once lost, diversity of gene pools cannot be restored
}

\author{
Michael T. Clegg
}

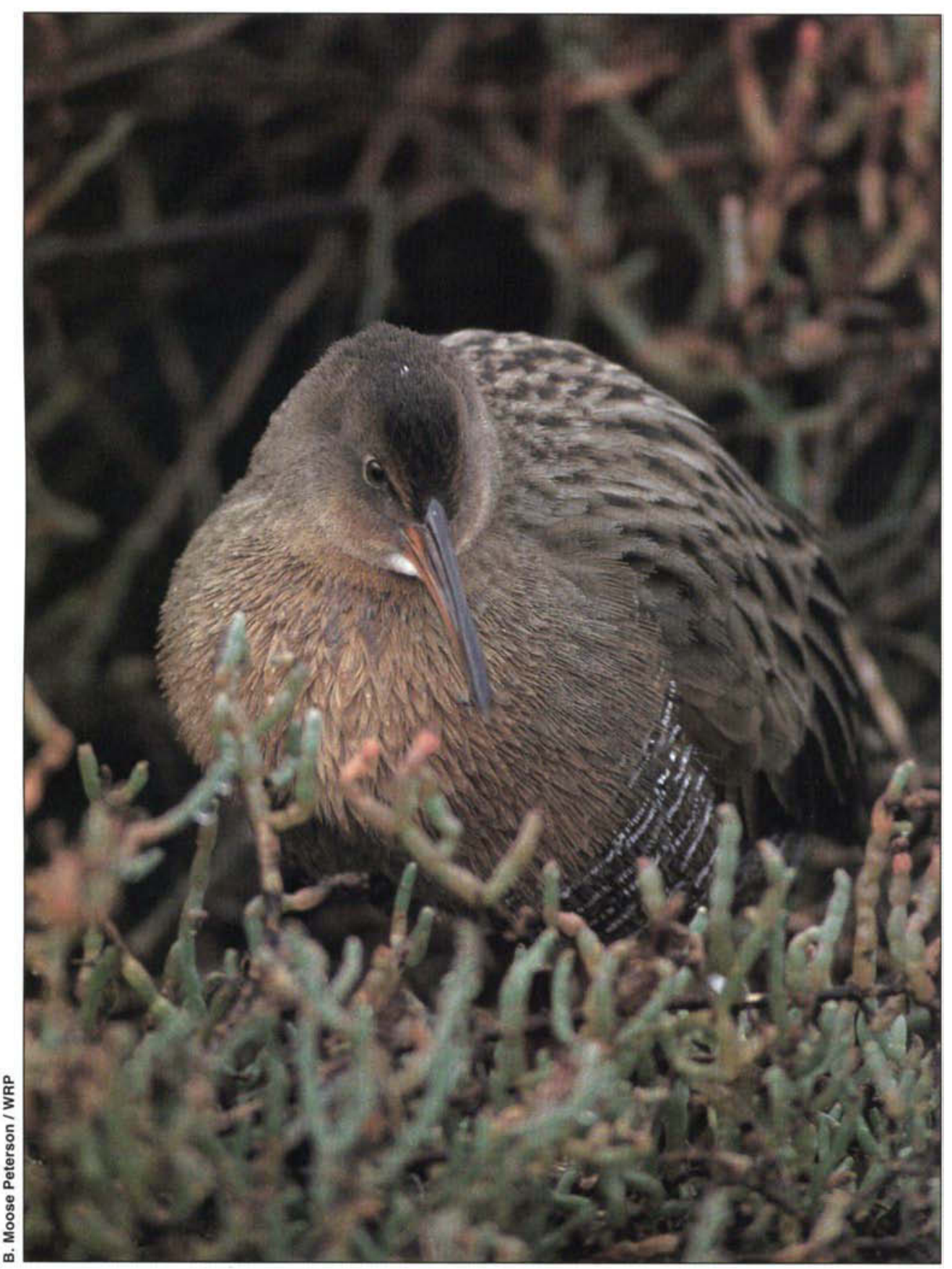

Nationwide, loss of wetlands has attracted scrutiny; $\mathbf{5 0} \%$ of animals and $\mathbf{3 3} \%$ of plants listed as endangered or threatened depend on wetland habitats. Above, the endangered California clapper rail.
The present diversity of species is the result of a very long and slow process of genetic change and adaptation. The time necessary for the emergence of new species, and even for the accumulation of genetic variants at individual gene loci within species, greatly exceeds the time since the emergence of Homo sapiens. New techniques of molecular biology combined with recent theories in population genetics allow us to assess the time dimension of genetic change; these suggest that some genetic polymorphisms may have originated over a million generations ago. In other words, once lost, any particular genetic adaptation cannot be regained in any realistic time interval. We depend on biological systems for food, fiber, energy and medicinal needs. Continued advances in each of these areas may be compromised by losses of the biological resources - that is the genetic variants - that provide the raw material for innovation.

T omo sapiens arose and became the 1 dominant species on earth in the last $1 / 20,000$ of the time elapsed since the origin of life. In this relatively short time, humans have altered both the physical and the biological worlds in profound ways. Our fossil fuel consumption and deforestation practices have substantially increased the concentration of carbon dioxide in the atmosphere, and our population growth is driving a major episode of biological extinction.

The changes that we are making in our environment are detrimental not 


\section{Hot-button issues for Endangered Species Act reauthorization}

\author{
Patrick Y. O'Brien
}

only to biological diversity but also to ourselves. The biodiversity that surrounds us provides us with food, fiber, medicine and energy. The accumulation of this biodiversity has been a very slow process when measured in human timescales. Biodiversity is the product of a vast history of evolutionary change - about 3.5 billion years. The colonization of the terrestrial environment by lifeforms began approximately 500 to 600 million years ago, and during this most recent $10 \%$ of evolutionary history all of the diverse forms of terrestrial life that comprise our environment appeared. We can not repopulate our world with species that have been lost, nor can we expect to regain the use of lost genetic variants within the timescale of human existence.

To gain perspective on our biological resources and to formulate wise strategies for managing our world, we must consider the following questions: What do we know about the processes that have produced the biological diversity of our world? And how have we attempted to place a value on biological diversity through our conservation activities?

\section{Timescales and diversity}

How long does it take to acquire the unique genetic attributes that mark distinct species? The temporal thread that binds generations is the transmission of the hereditary information encoded in DNA (deoxyribonucleic acid). The preservation of form and function depends on a highly efficient system for the replication of DNA, so that the information transfer from one generation to the next is nearly errorfree. Paradoxically, some errors are essential to provide evolutionary flex-

continued on page 37 ter often conflicts with the habitat needs of other species, which means This is the basic friction point that sparks most of the issues included in

Twenty-two years after its passage and its future is uncertain. More than vamp the ESA, especially to relieve burdens on private landowners. In gent mandates on public agencies as well as on private parties, environmentalists feel that it should be strengthened because humans are placing increasing stress on ecosysA variety of measures, some already embraced in policies adopted by Secretary of Interior Bruce Babbitt to depopulation declines in a number of species with popular appeal such as the bald eagle, the peregrine falcon, the grizzly bear and the timber wolf. Despite public surveys which show that most Americans support the

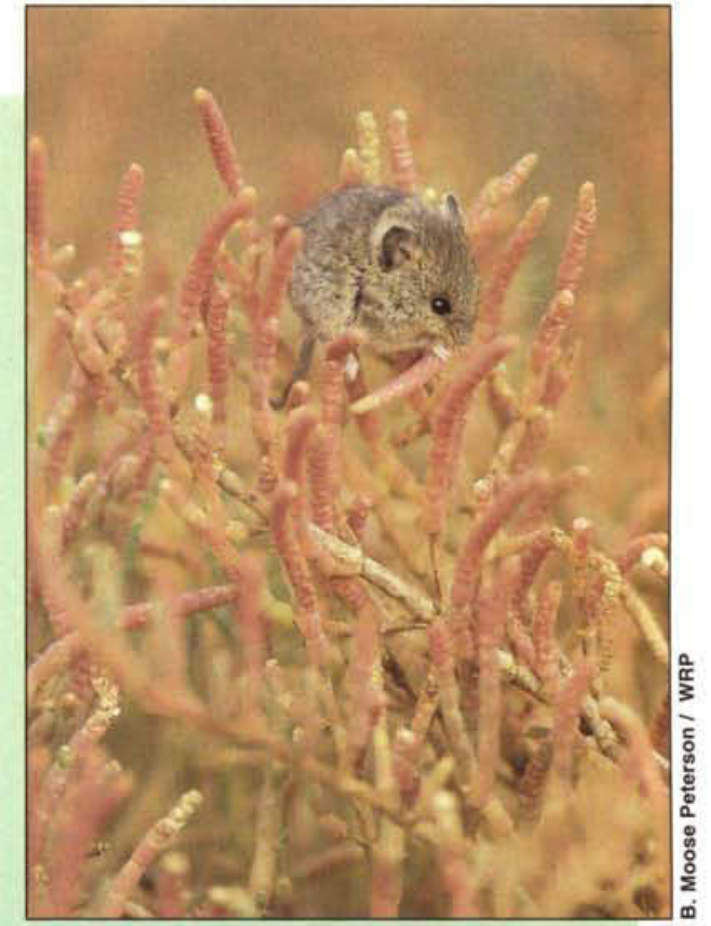

The Endangered Species Act (ESA) establishes protection of threatened and endangered species as a national goal. However, human use of land and wathat protective measures can interfere with economic development and other socially beneficial public works projects. the debate over reauthorizing the ESA. in 1973, the ESA is under heavy attack ever before, Congress is inclined to recontrast, the ESA's defenders feel that many of the proposed reforms will increase the likelihood of species' extinction. Although the ESA imposes strintems that support endangered species. fuse the mounting pressure for reform, could make the ESA more palatable to private landowners, while retaining its basic protective structure and features.

The ESA was originally inspired by
Conflicts have arisen over protection of habitat for endangered species including the salt marsh harvest mouse.

ESA's goals, many people view the law itself as inflexible, unfair to private landowners, unresponsive to certain social and economic factors, marginally successful, and a surrogate for other agendas. These arguments have all been made before, but last fall the public signaled a change in sentiment by electing legislators who were receptive to them.

One controversial aspect of the ESA is that in addition to protecting the highly visible species that appeal to the public, the Act also protects relatively obscure species. When the presence of an obscure species restricts the use of land or water, it creates controversy. Examples abound: in California alone, the Delta smelt has disrupted water deliveries to Central Valley agriculture; the Stephens and Tipton kangaroo rats have restricted cultivation practices in Southern California and the San Joaquin Valley, respectively; the California gnatcatcher has created tremendous uncertainty over the future of real estate development in coastal southern counties; and the northern spotted owl has dampened timber harvesting in the north.

Another controversial aspect of the ESA is that it allows the listing of plant 
and animal subspecies as well as of distinct population segments of vertebrate animals. This aspect has allowed for protection of the bald eagle, southern sea otter, timber wolf and grizzly bear in the lower 48 states even though healthy populations of the same species exist in Canada and Alaska. In addition, scientists disagree about whether some groups of animals, such as the California gnatcatcher and Alabama sturgeon, should qualify as subspecies and therefore be accorded legal protection. Subspecies definitions are often subjective because there is little scientific consensus about what criteria should be applied to what taxonomic groupings.

Some ESA critics want to protect most plants and animals only at the species level, partly because it is difficult to identify subspecies and we lack sufficient data to understand their contribution to genetic variability in most cases. Many scientists counter that protecting subspecies is very likely to increase a species' genetic variability, thus fostering its adaptive potential and survival. They feel that methods for identifying distinct groupings should be improved to make this practice more reliable and credible.

ESA reformists also criticize another aspect of its implementation: disproportionately heavy expenditures on a relatively few species. The single species emphasis has probably been needed to save the California condor, whooping crane, black-footed ferret, Puerto Rican parrot, and Florida panther, whose numbers are still dangerously low. But ESA defenders and critics generally agree that management plans focusing on individual species are inadequate. Multispecies or ecosystemlevel planning would reduce the need for individual species listings, which produce added layers of regulatory complexity. However, due to their different objectives, ESA defenders and reformists will undoubtedly push for different mechanisms to implement multispecies plans.

Another point of contention is whether or not to consider the costeffectiveness of protecting species. Re- cent court settlements have required the U.S. Fish and Wildlife Service to accelerate its schedule for making decisions about listing several hundred high priority candidate species. This faster listing pace has intensified pressure to justify the cost-effectiveness of species protections. Environmentalists feel that cost-benefit analysis would put species at a major disadvantage because their intangible value has already been heavily discounted in the face of economic growth, and that making further tradeoffs would aggravate extinction risk.

The ESA requires federal agencies to ensure that actions they fund, authorize, or carry out are not likely to jeopardize threatened or endangered species, or their critical habitat. Critical habitat is considered those specific areas containing the physical and biological features essential for the conservation of the species. This "non-jeopardy" requirement is under siege by those who think that federal agencies should have more discretion to balance conservation objectives with their other responsibilities such as regulating timber harvests, generating electric power, and distributing water. Environmentalists fear that compromising the non-jeopardy requirement will create irreparable tears in the safety net the ESA affords for imperiled species.

Finally and perhaps most importantly, Congress will have to determine whether and how to regulate habitat on private lands. This comes about because Section 9 of the ESA prohibits "take" of endangered species and by regulation, threatened species. The ban on species take does not distinguish between public and private lands. Most of the unlawful actions included under the definition of "take" cause direct injury or mortality such as hunting, shooting, wounding, killing, capturing and so on. However, "take" also covers "harm" which has been interpreted in regulation to include disturbance of habitat that kills or injures wildlife by significantly impairing essential behavior patterns such as breeding, feeding or sheltering. Last summer the Supreme Court affirmed this interpretation in its decision on Sweet Home Chapter v. Babbitt, which challenged the regulatory definition of harm.

While it is clear that conserving species depends on protecting their habitat, many advocates of private landowner rights view the protection of habitat on private land as excessive intrusion by the federal government. In a move widely hailed by ESA reformists, the House of Representatives recently passed a bill that would require compensation for landowners who suffer greater than $20 \%$ loss of property value due to government regulations. The Senate has not yet taken action on this measure.

Because so many species needing protection occur on private lands, new approaches are urgently needed to encourage cooperation among landowners. Secretary of Interior Babbitt has recently tried to show the ESA can be flexible enough to allay at least some landowners concerns. His "no surprises" and small landowner exemption policies attempt to ease the regulated community's fears about the barriers created when a listed species is found in the path of a development project. "No surprises" aims to assure landowners that conservation planning efforts that consider unlisted candidate species will not be invalidated if these species are later listed. Proposed federal rules would also create an exemption from the taking ban on threatened species for certain small projects. Reformists say that these policies are a good start but that they need to go further and be memorialized in legislation. Some environmentalists view these initiatives as helpful to resolving ESA conflicts while others feel they are useless attempts to appease landowners in the face of political pressure.

In addition, many feel that the current law creates perverse incentives for landowners to eliminate habitat out of fear that threatened and endangered species will occur on their property. This is clearly counterproductive and needs to be outweighed by incentives to protect habitat. Ways of easing the burden on private landowners and 
of increasing their confidence in the ESA include:

1. Encouraging voluntary conservation management agreements such as tax benefits for committing land to conservation.

2. Providing "safe harbor" exemptions when listed species colonize protected habitat.

3. Offering habitat credit trading systems that enable habitat units to be readily bought and sold in order to facilitate both mitigation and conservation objectives.

4. Writing restrictions that can be relaxed when local conservation planning goals are met.

5. Tailoring "take" rules to specific land use activities such as oil well drilling, plugging and abandonment operations.

6. Authorizing general permits for certain categories of ongoing operations and maintenance activities such as right of way or fire safety clearances that have minimal adverse effects.

7. Providing public funding for habitat conservation planning efforts.

8. Passing an amendment to the ESA that memorializes the "no surprises" policy and extends it by stipulating that no newly listed species will invalidate existing conservation agreements.

10. Expediting small project permits by amending the Section 10(a) incidental take permit process to eliminate Environmental Assessments, internal Section 7 consultations and multiple levels of administrative review for small projects that do not trigger interagency consultations.

11. Stressing and including greater landowner participation in recovery programs.

The above actions would also reduce the need to compensate landowners for economic loss, also a necessary feature of ESA administration, but preferably the one of last resort.

P.Y. O'Brien is Team Leader, Ecology, Cheoron Research and Technology Company, Richmond. continued from page 35

ibility. The ultimate source of biological diversity derives from mutational change in DNA molecules.

Owing to the powerful tools of molecular biology, our understanding of the genetic dimension of evolutionary change has advanced enormously over the past decade. These tools have provided us with a direct means of studying the pattern of mutational changes in DNA molecules among diverse life forms. Based on comparative studies, we now know that the error rate for DNA replication is very low (approximately $5 \times 10^{-9}$ base substitutions per nucleotide per year) (Nei 1987). We have also learned that a number of mechanisms cause mutational change, including the insertion and deletion of DNA sequences and the transposition of DNA sequences (e.g., with respect to the chloroplast genome, see Clegg, et al. 1994).

How can we learn about evolutionary time scales from the analysis of DNA sequence differences either among species or among individuals within a species? If we can determine the number of mutations that separate different species and if the mutation rate is constant, we can calculate the time it took to accumulate the observed level of mutational divergence. This notion of a molecular clock has been widely employed in evolutionary biology. To cite but one example of a molecular clock argument, it is estimated from the accumulation of mutational change in molecules that the monocotyledonous class of flowering plants (e.g., grasses, palms, orchids) separated from within the dicotyledonous class (e.g., cotton, sunflowers, apple trees and so on) approximately 200 million years ago (Wolfe et al. 1989).

Let us move from these ancient events in terrestrial evolution to the accumulation of genetic diversity within species. A commonly accepted definition of species is a group of individuals that are able to breed with each other (Mayr 1963). As a consequence, the members of a species share a common gene pool. As the populations that compose a species diverge from one another through time, barriers to reproduction begin to emerge. These include chromosomal rearrangements, behavioral divergence and changes in flowering time. New daughter species are born. The essential characteristic of a species is that the members share a common evolutionary future.

How extensive is the genetic diversity contained within species' gene pools? What factors control diversity levels and how long does it take to reach a given degree of diversity within a species' gene pool? According to biochemical assays of genetic diversity conducted over the past 25 years, most of the 470-plus tested plant species have extensive levels of genetic diversity (Hamrick and Godt 1989) and essentially the same is true of animal species. Plant and animal breeders exploit genetic diversity to improve domesticated species. Similarly, natural selection depends absolutely on genetic diversity to produce adaptive responses to environmental changes.

Levels of genetic diversity within species are controlled by mutation rates, the size of the breeding population (effective population size), and the pattern and strength of natural selection. (Effective population size is calculated as the harmonic mean of population sizes taken over time.) While mutation rates are reasonably constant across most life forms, patterns of effective population size and selection are highly specific and depend on the unique history of the species in question. For example, species that have expanded from glacial refugia may have much larger current numbers but their effective population size is still dominated by the bottleneck imposed by the glacial era. (Refugia are areas of relatively unaltered climate inhabited by plants and animals during a period of continental climatic change.) Hence the time it took to achieve a given degree of genetic diversity depends on the species.

The age of genetic variants within a species can be estimated by coalescence theory (Hudson 1990). Coalescence theory is a recent development in population genetics that relates mutational diversity for a particular gene to past episodes of selection and to the 
effective population size of the species. The effective population size can, in turn, be related to the age of genetic variants. To apply coalescence theory, researchers obtain DNA from a sample of individuals. For each individual, DNA sequence data are determined for a specific gene. According to the theory, the present-day sequences all trace back to a common ancestral sequence called the coalescent. The age of the coalescent depends on mutation rate and effective population size. Gene genealogies can also be used to detect natural selection.

Coalescence theory has been used to estimate the coalescent and the effective population size in two major grain crops (maize and pearl millet) using DNA sequences of the gene encoding the enzyme alcohol dehydrogenase 1 (Adh1) from wide geographic samples (Gaut and Clegg 1993a,b). These analyses revealed that the time to the coalescent for maize was nearly 2 million years and that the historical effective population size in maize was surprisingly large $(660,000)$. We might have expected the strong selection associated with the domestication of maize to have led to smaller effective population sizes. The coalescent for pearl millet was estimated to be about 500,000 years and the historical effective population size was about one quarter of that for maize. The interesting point is that in both maize and pearl millet, the stores of genetic diversity at the Adh1 locus have accumulated over long periods of time. For example, some of the common genetic variants of maize Adh1 were in existence during the era of Homo erectus (McHenry 1995) 1.6 million years ago, long before the appearance of modern humans.

Genetic diversity is useful to agriculture because crop improvement is based on the exploitation of useful genetic variants. It is also important to recall that species lacking present utility may still have value. They may contribute to ecosystem services such as photosynthesis, carbon recycling and so on, services that are essential for human life. They may also have direct but unanticipated future value (e.g., the Pacific yew, which is a source of taxol, the anticancer drug).
Much of the diversity in agricultural crops and their close relatives is being lost due to habitat destruction and the expansion of modern crop monocultures (the cultivation of one species or variety over large areas). To counteract this diversity loss, there has been a major international effort to collect and store the genetic resources crucial to continued agricultural improvement (Cohen et al., 1991).

In deciding to invest substantial resources in this international scheme for maintaining germplasm banks, we have essentially placed a value on the genetic diversity accumulated in crop species. This can also be calculated using what we have learned from coalescence theory (Clegg 1993). If we assume that it would take hundreds of thousands of years to restore genetic diversity once it was lost, we may approximate the future cost of genetic diversity loss in economically important species by applying a modest rate of interest to a crop's value (say $1 \%$ a year for several hundred thousand years).

\section{Space needed for evolution}

Species are composed of systems of populations called metapopulations (Levins; 1970) that are spread across an environment or landscape. A given environment is spatially heterogeneous (Risser, 1987), that is, local environments differ from each other. In each local environment, particular genetic variants of a species are more likely to survive and reproduce successfully, and natural selection favors those variants. Over time a given population adapts to its local environment. While genetically different, these locally adapted populations remain part of the same species because genetic migration among populations maintains a common evolutionary trajectory for the species as a whole.

Species cannot exist as dynamic evolutionary entities without sufficient habitat. (Imagine a forest of Douglas fir without habitat!) One of the most fundamental generalizations of ecology is the relation between the size of a habitat and the number of species that can live there (McArthur and Wil- son 1967). Reducing the size of a habitat means reducing the number of species that live there. In addition, habitat loss can ultimately reduce the ecosystem services required to sustain human activities.

The enormous expansion of the global human population has engendered an unavoidable conflict between biological diversity and the activities necessary to accommodate population growth. The battle field is habitat. To expand our agricultural, urban, industrial and other needs, we must convert habitat that supported a variety of biological activities into space for human use. How do we manage the environment to sustain human life in the long term while still meeting the needs of present populations? The obvious answer is that we adopt societal rules to conserve habitat and thereby to conserve the biological heritage upon which we depend.

\section{Conservation and the ESA}

The United States has had a long tradition of conservation, perhaps beginning with the creation of the $\mathrm{Na}$ tional Park system around the turn of the century. The bulk of federal funds for land conservation activities is provided by the Land and Water Conservation Fund. Since 1964, federal agencies have spent more than $\$ 3.6$ billion to acquire land; in addition, the federal government has provided $\$ 3.2$ billion in matching funds to states for land conservation activities (National Research Council 1993).

Federal agencies charged with promoting conservation are also responsible for regulating the uses of both public and private lands. The most potent legislation for biological conservation is the Endangered Species Act (ESA), first passed in 1973, and subject to 5-year reauthorization cycles. Section $2 \mathrm{~b}$ of the ESA states, "The purposes of this Act are to provide a means whereby the ecosystems upon which endangered species and threatened species depend may be conserved." The primary federal agencies charged with developing and enforcing the Act's regulations are the U.S. Fish and Wildlife Service and the National Marine Fisheries Service. 
The ESA defines "species" broadly to include any subspecies of plant or animal, as well as any distinct population segment of any vertebrate species that interbreeds when mature (Section $3,15)$. Although the term "species" is used more restrictively for plants and invertebrates than for vertebrates, there is no biological basis for such a distinction (National Research Council, 1995).

The ESA provides a means for listing species as threatened or endangered. At the time of listing, Section 4 of the Act generally requires the designation of critical habitat by the Fish and Wildlife Service that is essential for conserving the species. Section 9 of the Act prohibits taking a listed species, which is interpreted to include both injuring or killing the species and significantly modifying or degrading its habitat. The prohibition against take is enforced by significant legal and civil penalties. Section 11 of the act defines criminal penalties with fines up to $\$ 50,000$ or 1 year in prison.

To give the Act flexibility, Section 10(a) provides for incidental take associated with Habitat Conservation Plans (HCPs). While these plans require complex negotiations among private parties, local and state governments, HCPs are seen increasingly as a means of developing regional approaches to conservation in California.

The ESA's impact on both private and governmental land use has grown as conflicts between development and species conservation have become more frequent. The scheduled reauthorization of the Act was deferred in 1993. It seems likely that some, perhaps major, changes will occur in the law when it is reauthorized in 1996.

\section{Saving our ultimate resource}

The loss of species and valuable gene pools is proceeding at an accelerating pace. Once gone, this lost genetic diversity will not be regained for a long time - vastly longer than the total history of human existence. Man depends on the biological world for survival. Other species are the ultimate source of the energy, food, fiber and many of the medicines that we consume. While we have managed to convert the biological and physical resources of the earth to human use with increasing efficiency, we have simultaneously degraded the resource base for future human generations. This, coupled with a vastly expanding human population, threatens our ability to sustain our current standard of living into the future.

The United States has a long history of conservation policy aimed at preserving useful genetic variants for agriculture as well as ecosystems that are crucial to the quality of human life. Today, population pressures are intensifying the conflict between the need to preserve biological resources and the need of an expanding population to use land and raw materials. A major challenge for the 21 st century will be to develop approaches to conservation that meet our obligations to both present and future generations.

M.T. Clegg is Acting Dean, College of Natural and Agricultural Sciences, and Professor, Department of Botany $\mathcal{E}$ Plant Sciences, UC Riverside.

Statements in this review can be documented from the literature listed below. For additional references, contact the author.

\section{For further reading}

Clegg, M.T. 1990. Dating the monocot-dicot divergence. Trends Ecol. Evol. 5:1-2.

Clegg, M.T. 1993. Molecular evaluation of plant genetic resources. In Gene Conservation and Exploitation, J.P. Gustafson, R. Appels and P. Raven (eds). 20th Stadler Genetics Symposium. Plenum Press, New York.

Clegg, M.T., Gaut, B.S., Learn, G.H. and Morton, B.R. 1994. Rates and patterns of chloroplast DNA evolution. Proc. Natl. Acad. Sci. USA 91: 6795-6801.

Cohen, J.L., J.T. Williams, D. L. Pluckett and H. Shands. 1991. Ex situ conservation of plant genetic resources: Global development and environmental concerns. Science 253: pp866-872.

Gaut, B.S. and M.T. Clegg. 1993a. Molecular evolution of the Adh1 locus in the genus Zea. Proc. Natl. Acad. Sci. USA 90: pp5095-99.
The ultimate source of biological diversity derives from mutational change in DNA molecules.

Gaut, B.S. and M.T. Clegg. 1993b. Nucleotide polymorphism in the Adh1 locus of pearl millet (Pennisetum glaucum) (Poaceae). Genetics 135: 1091-97.

Hamrick, J.L. and M.J. Godt. 1990. Allozyme diversity in plant species. In Plant Population Genetics, Breeding and Genetic Resources. A. H.D. Brown, M. T. Clegg, A.L. Kahler and B.S. Weir, (eds.). Sinauer Associates, Sunderland, MA.

Hudson, R.R. 1990. Gene geneologies and the coalescent process. Oxford Surveys in Evol. Biol. 7: 1-44.

Levins, R. 1970. Extinction. In Some Mathematica/ Questions in Biology, Vol II M, Gerstenhaber, ed. American Mathematical Society, Providence, RI.

Mayr, E. 1963. Animal Species and Evolution. Belknap Press of Harvard University Press. Cambridge, MA.

McArthur R.H., and Wilson, E.O. 1967. The Theory of Island Biography. Princeton University Press, Princeton, N.J.

McHenry, H.M. 1995. Tempo and mode in human evolution. In Tempo and Mode in Evolution: Genetics and Paleontology 50 After Simpson. W.M. Fitch and F.J. Ayala eds. National Academy Press, Washington, DC.

National Research Council. 1993. Setting Priorities for Land Conservation. National Academy Press, Washington, DC.

National Research Council. 1995. Science and the Endangered Species Act. National Academy Press, Washington, DC.

Nei, M. 1987. Molecular Evolutionary Genetics. Columbia University Press, New York.

Risser, P. G. 1987. Landscape ecology: state of the art. In Landscape Heterogeneity and Disturbance. M. G. Turner, ed. Springer-Verlag, New York.

Wolfe, K. H., M. Gouy, Y.-W. Yang, P. M. Sharp and W.-J. Li. 1989. Date of the monocotdicot divergence estimated from chloroplast DNA sequence data. Proc. Natl. Acad. Sci. USA 86: $6201-05$. 